\title{
Türkiye'de Sürdürülebilir Tarım ve İyi Tarım Uygulamaları
}

\author{
Gamze AYDIN ERYILMAZ D 1 , Osman KILIÇ iD 2 \\ ${ }^{1}$ Ondokuz Mayıs Üniversitesi, Samsun Meslek Yüksekokulu, Park ve Bahçe Bitkileri Bölümü, Samsun, ${ }^{2}$ Ondokuz Mayıs Üniversitesi, Ziraat \\ Fakültesi, Tarım Ekonomisi Bölümü, Samsun
}

$\bowtie$ : gamzeaydin@omu.edu.tr

\begin{abstract}
ÖZET
Dünyada iyi tarım uygulamaları, gıda güvenliği ve kalitesinin sağlanması amacıyla ilk defa Avrupa'da başlamıştır. Türkiye'de 2007'de 18 ilde başlayan iyi tarım uygulamaları, verilen desteklerin etkisiyle son üç yılda büyük gelişme göstermiştir. Ancak iyi tarım uygulamalarının devamlılığı açısından, bu ürünlere olan talebi artırmanın önemi büyüktür. İyi tarım uygulamalarında tüketiciyi dikkate alan bir pazarlama anlayışının benimsenmesi firmalar arasındaki rekabeti hızlandıracak, buna bağlı olarak iyi tarım ürünlerinin üretimi artacaktır. Bu makalede, dünyada iyi tarım uygulamalarının gelişimi ve Türkiye'deki yansımaları ortaya konulmuştur.
\end{abstract}

\section{Sustainable Agriculture and Good Agricultural Practices in Turkey}

\begin{abstract}
Good agricultural practices (GAP) first initiated in Europe to provide food security and quality. Good agricultural practices in Turkey have been started at 18 provinces in 2007 and it showed great development due to increasing subsidies within the last three years. However, it is important to increase the demand to these products in order to sustain GAP. Adoption of a marketing strategy considering consumers' preferences will probably increase the production as well as competition among companies involved in this process. In this paper, developments of GAP in the world and its reflections over Turkey have been examined.
\end{abstract}

DOI:10.18016/ ksudobil. 345137

\section{Makale Tarihçesi}

Geliş Tarihi : 19.10.2017

Kabul tarihi : 15.01.2018

\author{
Anahtar Kelimeler \\ Sürdürülebilir tarım, \\ iyi tarım uygulamaları, \\ konvansiyonel tarım
}

\section{Derleme Makale}

\author{
Article History \\ Received : 19.10.2017 \\ Accepted : 15.01.2018
}

\section{Keywords \\ Sustainable agriculture, good agricultural practices, conventional agriculture}

\section{Review Article}

To cite : Aydın Eryılmaz G, Kılıç O 2018. Türkiye’de Sürdürülebilir Tarım ve İyi Tarım Uygulamaları. KSÜ Tarim ve Doğa Derg 21(4): 624-631. DOI:10.18016/ ksudobil. 345137

\section{GİRIŞ}

Dünya nüfusundaki artışla birlikte, artan tarım ve gida ürünleri ihtiyacının karşllanmasında, yoğun girdili tarımsal uygulamalar önem kazanmıştır. Bu durum, konvansiyonel tarım olarak adlandırılan üretim şeklinin yaygınlaşmasını hızlandırmıştır. Tarımda yoğun girdi kullanımına dayanan hızlı değişim, tarımsal üretimin daha az işgücüyle yapılabilmesine olanak sağlamıs, ancak konvansiyonel tarımdan kaynaklanan önemli çevresel maliyetlerin de ortaya çıkmasına neden olmuştur.

Yoğun kimyasal girdi kullanımının yol açtı̆̆ı çevresel sorunlar, doğal kaynakların kendini yenileyebilir olduğuna dair varsayımlar nedeniyle, uzun süre dünya gündeminden uzak kalmıştır. Diğer taraftan İkinci Dünya Savaşı'ndan sonra ülkelerin önceliğini; ekonomik kalkınmanın hızlandırılması, işsizliğin önlenmesi ve enflasyonun kontrol altına alınması gibi konular belirlemiştir. Bu çerçevede oluşturulan

kalkınma politikalarında ağırlık üretim artışına verildiği için, gelişmiş ve gelişmekte olan ülkelerde çevre bilincinin oluşması gecikmiştir (Dulupçu, 2000). Çevresel sorunlar, İkinci Dünya Savaşı sonrası yoğun tarımsal faaliyetler sonucunda, insan ve doğa arasındaki dengenin giderek doğa aleyhine bozulmasiyla (Tiraș, 2012) bütün ülkelerde önem kazanmaya ve tartışılmaya başlanmıştır.

Çevresel sorunların uzun vadede öngörülen etkileri küresel nitelikte olup, bu durum sosyal ve ekonomik sorunları beraberinde getirmektedir. Doğal kaynakların tahrip olmasıla birlikte, tarımsal ürünlerde dışa bağımlılık, kırsal alandan kentlere göç, kırsal toplum özelliğinin yok olması, kırsal ve kentsel nüfus dengesizliğinin artması gibi başlıca sorunlar ortaya çıkmaktadır. Konvansiyonel tarımla gündeme gelen bu sorunlar, gelecek nesiller için doğal kaynakları koruyan ve çevreye zarar vermeyen tarımsal üretim tekniklerinin kullanıldığı sürdürülebilir tarım anlayışını ortaya çıkarmıştır. Tarım ve çevre arasında dengeli bir ilişkinin varlığını 
açıklayan sürdürülebilir tarım, doğal kaynakların gelecekte de yarar sağlayacak şekilde yönetilmesini zorunlu kılmaktadır (Dişbudak, 2008).

Sürdürülebilir tarım konusunun dünyada önem kazanmasiyla birlikte, son yıllarda bu konuda yapılan bilimsel çalışmaların sayısında artış olmuştur. Sürdürülebilir tarımın tanımını, prensiplerini ve dünyadaki gelişimini kavramsal olarak ortaya koyan çalışmaların (Safley, 1998; Aerni, 2009) yanı sıra, özellikle sürdürülebilir tarımı çevresel, ekonomik ve sosyal etkileriyle ele alan çalışmaların sayısı artmıştır. Sürdürülebilir tarım sistemlerinden biri olan iyi tarım uygulamaları konusunda da çeşitli çalışmalar yapılmıştır. $\mathrm{Bu}$ çalışmalarda; iyi tarım uygulamalarına yönelik politikalar (Ataseven, 2014), çiftçilerin tutum ve davranışları (Marine ve ark., 2016; Amekawa ve ark., 2017), iyi tarım uygulamaları yapan ve yapmayan işletmelerin çeşitli yönlerden karşılaştırılması (Subaşı ve ark., 2016) gibi konular incelenmiştir. Bu makalede; sürdürülebilir tarım ve iyi tarım uygulamalarıyla ilgili kavramsal bilgilere yer verilmiş, iyi tarım uygulamalarının dünyadaki gelişimi ile bu gelişmelerin Türkiye'deki etkileri ortaya konulmuştur.

\section{SÜRDÜRÜLEBİLİR TARIM}

Dünyada sürdürülebilirlik kavramının yaygın olarak kullanılması 1980'li yıllara dayanmaktadır. Kökeni Latince "Sustinere" kelimesinden gelen kavram; sürdürmek, sağlamak, devam ettirmek, desteklemek ve var olmak anlamlarında kullanılmaktadır (Onions, 1964). Üretim, tüketim, ticaret ve büyüme gibi ekonomik alanlar ile kültürel, siyasal, sosyal ve çevresel alanlarda kullanılan sürdürülebilirlik kavramı, kısaca bugünkü kaynakların gelecek nesillere kayıpsız bir şekilde aktarılması anlamına gelmektedir (Kuşat, 2013).

Sürdürülebilirlik kavramı yeni bir fikir olarak görünmesine rağmen, geçmişi sosyal adalet, korumacılık, enternasyonalizm gibi hareketlere dayanmaktadır. $\mathrm{Bu}$ hareketler, yirminci yüzyılın sonuna doğru sürdürülebilir kalkınma adıyla bir araya getirilmiştir. Sürdürülebilir kalkınma; genel olarak sağlıkl, gelişen ve kazanımların büyük ölçüde dengeli dağıtılmasını sağlayan bir ekonomi sayesinde, insan hakları ve özgürlüğü garanti altına alan politik bir sistemi hedeflerken, etkili liderlik sayesinde de çevrenin korunmasını göz önünde bulunduran politikaların oluşturulmasını amaçlamaktadır (Çelik, 2006). Doğanın her türlü dış müdahaleye karşı koyabilme ve maruz kaldığı hasarlara karşı kendini yenileyebilme kapasitesi sinırlıdır. $\mathrm{Bu}$ yüzden kalkınma sürecinin her aşamasında çevreyi ve doğal kaynakları korumak, insana yüklenen sosyal sorumlulukların başında gelmektedir (Boz ve ark., 2013).

Çevre sorunu, ilk defa 1968'de Roma Kulübü'nün
İnsanlı̆̆ın Geleceğinin Tahmini Projesi ve daha kapsamlı olarak 1972'de Birleşmişs Milletler tarafından Stockholm'de düzenlenen İnsan-Çevre Konferansı'yla resmi olarak dünya kamuoyuna duyurulmuştur (Davran, 2007). Uluslararası boyuttaki bu konferans, çevresel sorunların küresel boyutu ve kapsamı bakımından bir dönüm noktası olmuştur. Nitekim ekonomik ve sosyal gelişmenin çevreyle bağlantısını vurgulayan ilkelerin geliştirilmesi, birçok ülkenin çevre politikalarını etkilemiştir. Çevresel sorunların çözümünü içine alan sürdürülebilir kalkınma kavramı, resmi olarak ilk defa 1987'de Gro Harlem Brundtland tarafindan Dünya Çevre ve Kalkınma Komisyonu için hazırlanan Ortak Geleceğimiz Raporu'nda tanımlanmıştır (Özmehmet, 2008). Raporda sürdürülebilir kalkınma, genel olarak bugünkü nesillerin gıda maddeleri gereksinimlerini karşılarken, gelecek nesillerin gida maddeleri gereksinimlerini karşılama talepleri üzerine ipotek koymamalarını gerektiren bir kalkınma şekli olarak ifade edilmiştir (Anonim, 1987). Bu tanımdan hareketle Tatlıdil ve ark. (2009), günümüz nesillerinin kendi ihtiyaçlarını karşılarken, gelecek nesillerin yaşam kalitesini azaltma haklarının olmadığı ve her türlü ekonomik kalkınma girişiminde, doğal kaynaklar ile çevrenin korunmasına azami özen göstermeleri gerektiğini belirtmektedirler.

Dünyadaki en önemli çevresel sorunların başında yer alan iklim değişikliği ve çölleşme konuları, Birleşmiş Milletler tarafindan 1992 'de düzenlenen Rio Konferansı'nda gündeme getirilmiştir. Konferansta küresel ısınmayı durdurmak amaciyla, atmosfere salınan sera gazı miktarının sinırlandırılmasını hedefleyen Birleşmiş Milletler İklim Değişikliği Çerçeve Sözleşmesi 21 Mart 1994'de imzaya açılmıştır. Çerçeve sözleşmesinin ilkeler başlığı altında verilen 3’üncü maddesinde; "taraflar, iklim değissikliğinin nedenlerini önceden tahmin etmek, önlemek veya en aza indirmek ve zararlı etkilerini azaltmak için önleyici önlemler almalıdır" ifadesi yer almaktadır (Anonim, 2002).

Rio Konferansı'ndan sonraki on yıllın değerlendirmesini yapmak ve ileriye dönük kalkınma stratejilerini belirlemek amaciyla, 2002'de Güney Afrika Cumhuriyeti'nin Johannesburg kentinde Dünya Sürdürülebilir Kalkınma Zirvesi yapılmıştır. Toplumun tüm kesimlerinin katılımına öncelik verilen zirvede, çevre koruma ve yoksullukla mücadelede yeni veriler ortaya konulmuştur. Zirve kararlarının uygulanmasında, sivil toplum kuruluşlarının önemi ve işbirliğinin sağlanması konusu üzerinde durulmuştur (Yıldırım ve Öner, 2003). Zirve sonrası yayınlanan bildiride, ekonomik ve sosyal kalkınma ile çevrenin korunması başta olmak üzere sürdürülebilir kalkınmanın bileşenleri belirlenmiştir (Tıraş, 2012). Birleşmiş Milletler öncülüğünde, 2012'de yapılan Birleşmiş Milletler Sürdürülebilir Kalkınma 
Konferansı sonunda İstediğimiz Gelecek isimli sonuç bildirgesi yayınlanmıştır. Bildirge metninde, Rio prensipleri ve geçmiş eylem planları tekrar onaylanmıştır (Yeşil, 2016).

Sürdürülebilir kalkınma konusunda, Birleşmiş Milletler üyesi ülkeler ile paydaşların ortak hareket etmesini sağlayan Birleşmiş Milletler Sürdürülebilir Kalkınma Zirvesi 2015'de New York'ta gerçekleştirilmiştir. Zirvede, 193 ülke tarafından 2030 yılı sürdürülebilir kalkınma hedefleri kabul edilmiştir. Dünya barışının sağlanmasının amaçlandığı zirvede, sürdürülebilir kalkınma için küresel ortaklığın güçlendirilmesi gerektiği vurgulanmıştır (Anonim, 2016a). Yeni bir dönemin kapılarını açan sürdürülebilir kalkınma hedefleriyle; yoksulluğun ana nedenlerinin ortadan kaldırılması, ekonomik büyümenin ve refahın desteklenmesi, halk sağlığı, eğitim ve sosyal ihtiyaçların karşılanması için adımlar atılmış, aynı zamanda çevrenin korunması için yeni önlemler de alınmıştır (Anonim, 2016b).

Çevrenin ve doğal kaynakların tahrip edilmeden kullanılması amacıyla toprak işlemeden başlayarak, üretimin her aşamasında girdi kullanımının kontrol edilebildiği sürdürülebilir tarım, son yıllarda daha çok önem kazanmıştır. Kavramla ilgili farklı tanımlamalar yapılmakla birlikte, genel olarak bugün ve gelecek nesiller için gerekli olan doğal kaynakları koruyarak, insanların besin ihtiyacını karşılayan bir tarımsal üretim şekli olarak ifade edilmektedir. Sürdürülebilir tarımı; Turhan (2005) uzun dönemde doğal kaynakların korunduğu ve çevreye zarar vermeyen tarımsal teknolojilerin kullanıldığ bir yapı, Menalled ve ark. (2008) gelecekte gida, enerji ve doğal kaynak ihtiyacını karşılamakla birlikte toprak, su ve biyo-çeşitliliği koruyan bir uygulama şekli, Hess (1991) sadece insan sağlığını ve çevreyi koruyan bir üretim sistemi değil, aynı zamanda teknolojinin dengeli kullanılması ve doğru işletme yönetimini de kapsayan sistemler bütünü olarak tanımlamışlardır. Sürdürülebilir tarımda konuların ele alınması ve uygulanmasındaki öncelikler, ülkelerin gelişmişlik düzeylerine göre farklılık göstermektedir. Sürdürülebilir tarım, gelişmekte olan ülkelerde gıda güvenliği ve yoksullukla mücadelenin önemli bir unsuru iken (Adenle ve ark., 2012), gelişmiş ülkelerde daha çok çevre kalitesi ve kullanılan kaynakların insan sağlığı üzerindeki olumsuz etkileri, küçük işletmelerden kaynaklanan zorluklar ile kırsal alanda çölleşme gibi konular olarak ifade edilmektedir (Marsh, 1997; Gafsi ve ark., 2006).

Sürdürülebilir tarımın sosyal, ekonomik ve çevresel olmak üzere küresel düzeyde etkilere sahip üç temel bileşeni bulunmaktadır. Sürdürülebilirliğin sağlanması, bu bileşenler arasındaki dengenin korunmasıyla mümkün olmaktadır. $\mathrm{Bu}$ sayede tarımsal faaliyetlerin çevreye verdiği zararlar azaltılmakta ve tarımsal üretimin ülke ekonomisine katkısı devam etmektedir. Aynı zamanda geçimini tarımdan sağlayan nüfus yerinde istihdam edilerek, tarımsal nüfusun kırsal toplum olma özelliği korunmaktadır. Sürdürülebilir tarımın bileşenlerinden olan sosyal sürdürülebilirlik; işletme çalışanlarının ücretleri, üreticilerin yaşam kalitesi ve işletmedeki etik konuları, ekonomik sürdürülebilirlik; tarım işletmesinin kârlılığı, işletme masrafları, gelir değişkenliği, finansal riskler, gıda masrafları ve yatırım konularını içermektedir. Çevresel sürdürülebilirlik ise; enerji etkinliği, toprak ve su kalitesi, yaban hayatın korunması, gıda ve yem güvenliği ile işletme güvenliğini kapsamaktadır (Atış, 2004). Çevresel sürdürülebilir tarımın sağlanması, tarımsal faaliyetlerin ekonomik olmasıyla mümkün olmaktadır. Çevreyi ve doğal kaynakları koruyan tarımsal uygulamaların üreticiye yükleyeceği ilave maliyet, sürdürülebilir tarımın gelişimini etkileyecektir. $\mathrm{Bu}$ nedenle çevresel ve ekonomik bileşenleri birlikte değerlendirmek, sürdürülebilir tarımın uzun dönemde uygulanabilirliği açısından önemlidir.

\section{DÜNYADA IYI TARIM UYGULAMALARI}

Dünyada artan nüfusun besin ihtiyacını karşılamak için, kimyasal girdilerin yoğun kullanıldığı ileri teknolojik uygulamalara yer veren yöntemler geliştirilmiştir. Ancak bu yöntemlerin üretimi artırıcı etkilerine karşın, neden olduğu çevresel sorunlar 1960'ların sonu ile 1970'lerin başında artma eğilimi göstermiştir. Kalkınma sürecinin başında yerel ölçekli görülen çevresel sorunlar, daha sonra ülke sınırlarının ötesine taşmış, ortaya çıkan zararlar ise bölgesel ve uluslararası boyuta ulaşmıştır (Kaypak, 2011). Zamanla artan bu çevresel sorunlar, mevcut doğal kaynakların etkin kullanımına odaklanan sürdürülebilir tarım sistemlerinin geliştirilmesinin ilk adımını oluşturmuştur. Daha sonraki süreçte insan sağllğını ve çevreyi koruyan tarımsal üretimin sağlanmasında, sürdürülebilir tarım sistemlerinin yaygınlaştırılması önemli hale gelmiştir. $\mathrm{Bu}$ bağlamda, günümüzün en yaygın sürdürülebilir tarım sistemlerinden biri olan iyi tarım uygulamaları her geçen gün artmaktadır.

İyi tarım uygulamaları kavramı, son yıllarda hızlı bir şekilde değişen ve küreselleşen gıda ekonomisiyle ilgili paydaşların gıda üretimi ve kalitesi, gıda güvenliği, tarımın çevresel sürdürülebilirliği hakkındaki taahhütleri bağlamında ortaya çıkmıştır. $\mathrm{Bu}$ paydaşlar; orta ve uzun vadede gıda güvenliği, gıda kalitesi, üretim etkinliği, çevresel kazanımların belirli hedeflerini karşılayan gıda işleme ve perakende firmaları, çiftçiler, tarım işçileri ve tüketicileri kapsamaktadır (İçel, 2007). İyi tarım uygulamalarında kimyasal girdi kullanımı söz konusu olmakla birlikte, girdiler insan sağlığına ve çevreye zarar vermeyecek şekilde tatbik edilmektedir (Hasdemir, 2011). İyi 
tarım uygulamaları kontrollü bir tarımsal faaliyet olup, tüm uygulamaların kayıt altına alınmasını esas almaktadır. Bu kayıtlar; ürünün tür ve çeşidi, kullanılan gübre ve zirai ilacın uygulama nedeni, zamanı, miktarı, öneriyi yapanın ve uygulayıcının ismi, bu konudaki yetkinliği, ürünün kaç gün sonra hasat edileceği ve su kalitesini de kapsayan sulamayla ilgili tüm detayları içermektedir. Böylelikle iyi tarım uygulamalarında, izlenebilirlik ve sürdürülebilirlik yerine getirilmiş olmaktadır (Aksoy ve ark., 2013).

İyi tarım uygulamalarının çerçevesini belirlemek üzere, Avrupa perakendeciler ürün çalışma grubunun (EUREP), 1997'deki girişimiyle tarladan sofraya gıda güvenliği ve kalitesinin sağlanması hedeflenmiştir (Polat, 2014). EUREP, öncelikle yaş meyve ve sebzede iyi tarım uygulamalarına ilişkin esasları belirlemiş, 1999'da ise EUREPGAP protokolünü yayınlamıştır. Gıda ve Tarım Örgütü (FAO), iyi tarım uygulamalarını 2002'deki Dünya Sürdürülebilir Kalkınma Zirvesi’nde tarım ve kırsal kalkınmanın prensiplerinden biri olarak benimsemiştir. Aynı zamanda FAO, Dünya Ticaret Örgütü üyesi olan ülkelere EUREPGAP standartlarını referans ilke olarak kabul etmelerini önermiştir (Aba ve Işın, 2014). Avrupa ülkelerinin öncülük ettiği bu uygulama, yıllar içinde diğer ülkelere de yayılmıştır.

EUREPGAP ismi, protokolün küresel ticaret modeline uyum sağlaması amacıyla, Eylül 2007'de düzenlenen sekizinci ylllk konferansta GLOBALGAP olarak değiştirilmiştir. GLOBALGAP kapsamında; bitkisel ürünlere (meyve, sebze, çiçek, süs bitkileri, yeşil kahve, çay vb.), çiftlik hayvanlarına (sığır, koyun, süt hayvancılı̆̆ vb.) ve su ürünlerine (somon, karides, köpek balığ ve Işın, 2010). GLOBALGAP, tarım ürünlerinin sertifikasyonu için gönüllülük esasına bağlı standardizasyon oluşturulmasını sağlayan özel bir protokoldür. Bu protokol, iyi tarım uygulamaları için gerekli işlemlerin ve standartların sertifikasyonunu kurmak isteyen üretici ve pazarlamacıların eşit ortaklığından meydana gelmektedir. GLOBALGAP, tohum ekiminden başlayıp ürünlerin işletmeden ayrılıncaya kadarki standartlaştırma sertifikasyonunu kapsamaktadır (Baghasa, 2008). Avrupa Birliği ülkeleri, iyi tarım uygulamalarını içeren GLOBALGAP protokolüyle, dış alım yaptıkları meyve ve sebzelerin kontrollü ve sertifikalı olarak üretilmesi şartını getirmiştir. Günümüzde bu sertifika, dünya genelinde tarım ürünleri ticaretinde talep edilen en yaygın sertifikadır (Hasdemir, 2011).

Tarımda bilinçsiz ve aşırı girdi kullanımının ürünlerde bıraktığı kalıntıları en aza indirmek ve sürdürülebilir çevreyi sağlamak amacıyla, gelişmiş ülkeler başta olmak üzere birçok ülkede sürdürülebilir tarım sistemleri desteklenmektedir. Finlandiya'da 20072013 yılları arasında tarımsal faaliyetlerde kullanılan su kaynaklarının yol açtığı kirliliği azaltmak için,
Agri-Environmental Payments (AEP) adı altında parasal destekler verilmiştir. Almanya, Fransa, Hollanda ve İsviçre'de tarıma daha az elverişli alanların üretime katılmalarına yönelik olarak, 2009'da Payment-By-Results (PBR) ve Agricultural Environmental Schemes (AES) kapsamında destekler verilmeye başlanmıştır. Ayrıca Ekonomik İşbirliği ve Kalkınma Örgütü (OECD) üyesi ülkelerde, 2010'dan beri çevrenin korunması ve kültürel uygulamaların devamina yönelik olarak, Payments for Environmental Services (PES) adıyla çiftçilere teşvik ödemeleri yapılmaktadır (Türkten ve ark., 2014).

\section{TÜRKIYE'DE IYYI TARIM UYGULAMALARI}

Dünyada çevrenin korunmasına yönelik çalışmaların Türkiye'deki ilk yansımaları, 1972'de Stockholm'de düzenlenen konferansla gerçekleşmiştir. $\mathrm{Bu}$ gelişmeler, 1973-1977 dönemini kapsayan üçüncü beş yıllık kalkınma planında somutlaştırılmıştır (Davran, 2007). Kalkınma planında, sanayi ve yoğun kentleşme alanlarında hava, su ve kıyı kesimlerdeki kirlenme gibi çevresel sorunların yanında, eğitim ve gelir yetersizliği nedeniyle doğal kaynakların gerekli biçimde ve yeterince kullanılamamasıyla ortaya çıkan sorunlara değinilmiştir (Anonim, 1973). Konvansiyonel tarımın çevre üzerindeki etkilerine ilişkin senaryolar, son yıllarda daha çok tartışılmaya başlanmıştır. Senaryolarda, özellikle toprak ve su kaynaklarının tükenmesine bağlı olarak yaşanacak kıtlıklar, biyolojik çeşitliliğin zarar görmesi ve orman alanlarının yok olması gibi önemli çevresel sorunlar yer almaktadır. Dolayısıyla insanlığın ortak kaygısı haline gelen tarımsal kaynaklı çevresel sorunların azaltılmasında, sürdürülebilir tarım ve buna yönelik tarımsal uygulamalar öncelikli konular olarak ortaya çıkmaktadır.

Türkiye'de iyi tarım uygulamalarına ilişkin ilk yönetmelik, 08.09.2004 tarih ve 25577 sayll Resmi Gazetede yayınlanmıştır. Yönetmeliğin 1'inci maddesine göre iyi tarım uygulamalarının amaci; insan ve hayvan sağlığına zarar vermeyen, çevre dostu tarımsal bir üretimin benimsendiği, tarımda izlenebilirlik ve sürdürebilirliğin sağlandığı, doğal kaynakların korunmasının ve gida güvenliğinin amaçlandığ $\quad$ bir üretim modelinin gerçekleştirilmesidir (Anonim, 2004). Yönetmelik, iyi tarım uygulamalarıyla ilgili standartların kural ve koşullarını, belgelendirme işlemlerinin şeklini, kişi ve kuruluşların görev ve sorumluluklarını belirlemektedir (Hasdemir, 2011).

Türkiye'de 2007'de başlayan iyi tarım uygulamalarında, üretici sayısı ve üretim alanı bakımından özellikle 2013 sonrasında önemli gelişmeler olmuştur. İyi tarım uygulamalarının yapıldığı il sayısı 2007'de 18 iken, 2016'da 64'e çıkmıştır. İyi tarım uygulanan alan ise 10 yılda yaklaşık 88 kat artış göstermiştir (Çizelge 1). 
Türkiye'de 2016 yılı itibariyle, en fazla iyi tarım uygulanan alana sahip bölge \%48.89 ile Güneydoğu Anadolu Bölgesidir. Bunu \%16.56 ile Akdeniz, \%12.76 ile Ege Bölgesi takip etmektedir. En fazla iyi tarım uygulanan alana sahip iller sirasiyla Gaziantep (\%23.38), Şanlıurfa (\%16.86) ve Adana (\%7.85)'dır (Çizelge 2).

Çizelge 1. Türkiye'de iyi tarım uygulamaları

\begin{tabular}{llll}
\hline & $\dot{\text { Il sayıs }}$ & Üretici sayısı & Üretim alanı (da) \\
\hline 2007 & 18 & 651 & 53,607 \\
2008 & 19 & 822 & 60,231 \\
2009 & 42 & 6,020 & $1,702,804$ \\
2010 & 48 & 4,540 & 781,741 \\
2011 & 49 & 3,042 & 499,632 \\
2012 & 47 & 3,676 & 837,171 \\
2013 & 56 & 8,170 & 985,099 \\
2014 & 53 & 21,332 & $2,147,705$ \\
2015 & 61 & 39,740 & $3,465,695$ \\
2016 & 64 & 55,609 & $4,741,075$ \\
\hline
\end{tabular}

Kaynak: Anonim, 2016c

Türkiye'de iyi tarım uygulamaları desteği, ilk defa 29 Aralık 2010 tarih ve 27800 sayılı Resmi Gazete'de yayınlanan "İyi Tarım Uygulamalar Destekleme Ödemesi Yapılmasına Dair Tebliğ’le başlamıştır. Tebliğin 5'inci maddesinde ödeme yapılacak çiftçilerde aranan şartlar; "bireysel veya grup halinde meyve sebze üretiminde veya örtü altında iyi tarım uygulamaları yapan, yetkilendirilmiş kuruluşlarca düzenlenmiş iyi tarım uygulamaları sertifikasına sahip olan, çiftçi kayıt sistemine kayıtlı olan, örtü altında iyi tarım uygulamaları yapan çiftçilerden örtü altı kayıt sistemine kayıtl olan ve iyi tarım uygulamalarıla ilgili belirtilen usul ve esaslara göre başvuru yapan” şeklinde belirlenmiştir. Buna göre 2010'da iyi tarım uygulamaları desteği olarak, meyve ve sebze üretimi için dekara 20 TL ve örtü altı üretimi için dekara 80 TL ödeme yapılmıştır (Anonim, 2010). Daha sonra 13.06.2011 tarih ve 2011/006 sayll "Bitkisel Üretimde Iyi Tarım Uygulamaları Kriterleri Genelgesi", 11.07.2011 tarih ve 2011/8 sayll "Su Ürünleri Yetişstiriciliğinde İyi Uygulamalar Kriterleri Genelgesi", 14.10 .2011 tarih ve 2011/007 sayll "Hayvansal Üretimde $\dot{I}_{y i}$ Tarım Uygulamaları Kriterleri Genelgesi” yayınlanmıştır (Ataseven, 2014). İyi tarım uygulamaları desteği, 25 Mayıs 2013 tarih ve 28657 sayılı "Iyi Tarım Uygulamaları Destekleme Ödemesi Yapılmasına Dair Tebliğ'le, meyve ve sebze üretimi için dekara $25 \mathrm{TL}$ ve örtü altı üretimi için dekara 100 TL olarak düzenlenmiştir (Anonim, 2013). Destek, 12.04.2014 tarih ve 28970 sayıl Resmi Gazete'de yayınlanan "2014 Yllinda Yapılacak Tarımsal Desteklemelere Ilişkin Karar"la değiştirilmiştir. Bu karara göre 2014'de destekleme ödemesi, meyve ve sebze üretimi için dekara 50 TL ve örtü altı üretimi için dekara 150 TL şeklinde belirlenmiştir (Anonim, 2014). Destekler, 2017 yll itibariyle meyve ve sebze üretiminde dekara $50 \mathrm{TL}$, örtü altı yetiştiricilikte dekara $150 \mathrm{TL}$, süs bitkileri ve tıbbi aromatik bitkilerde ise dekara 100 TL olarak verilmektedir (Anonim, 2017).

\section{SONUÇ ve ÖNERILER}

Ülkelerin beslenme ve rekabet gücü kazanmalarına yönelik üretimlerini arttırma çabaları, tarımda yoğun girdi kullanımının giderek artmasına yol açmıştır. Dünyada yoğun girdi kullanımına dayanan konvansiyonel tarıma gösterilen bu ilgi uzun yıllar devam etmiştir. Ancak konvansiyonel tarımdan kaynaklanan çevresel sorunların ortaya çıkmasıla, kimyasal girdi kullanımının sürdürülebilir tarım üzerindeki etkileri tartışılmaya başlanmıştır. Bunun sonucu olarak konvansiyonel tarımın zararlı etkilerini azaltmak amaciyla, sürdürülebilir tarım sistemlerinden biri olan iyi tarım uygulamaları önem kazanmıştır.

Türkiye'de gıda güvenliği ve yoksulluk sorunlarının tam olarak çözülememesi, çevresel konuların gündeme gelmesini ve buna bağlı olarak iyi tarım uygulamalarının yaygınlaşmasını geciktirmiştir. İyi tarım yapan üretici sayısı ve uygulanan alana göre, Güneydoğu Anadolu bölgesi ilk sırada yer almaktadır. İnsan sağllğı ve çevrenin korunması göz önüne alındığında, diğer illerde de iyi tarım uygulamalarına yönelik çiftçi bilincinin artırılması gerekmektedir. 
Çizelge 2. Türkiye'de iyi tarım uygulayan üretici sayısı ve üretim alanı (2016)

\begin{tabular}{|c|c|c|c|}
\hline & \multirow[t]{2}{*}{ Üretici sayısı } & \multicolumn{2}{|c|}{ Üretim alanı } \\
\hline & & (da) & $(\%)$ \\
\hline Balıkesir & 1,377 & $158,098.88$ & 3.33 \\
\hline Çanakkale & 524 & $62,760.23$ & 1.32 \\
\hline Edirne & 89 & $63,596.34$ & 1.34 \\
\hline $\begin{array}{l}\text { Sakarya, Bursa, Tekirdağ, Yalova, Kırklareli, } \\
\text { Kocaeli, İstanbul, Bilecik }\end{array}$ & 501 & $69,508.73$ & 1.47 \\
\hline Marmara Bölgesi & 2,491 & $353,964.18$ & 7.46 \\
\hline Giresun & 1,782 & $20,482.75$ & 0.43 \\
\hline Samsun & 1,453 & $143,154.14$ & 3.02 \\
\hline Ordu & 893 & $59,034.84$ & 1.25 \\
\hline Artvin, Düzce, Trabzon, Sinop, Kastamonu, Çorum, & & & \\
\hline Tokat, Amasya, Bartın & 722 & $28,513.90$ & 0.60 \\
\hline Karadeniz Bölgesi & 4,850 & $251,185.63$ & 5.30 \\
\hline Elazığ & 204 & $17,027.10$ & 0.36 \\
\hline Siirt & 236 & $18,155.81$ & 0.38 \\
\hline Erzurum, Bitlis, Ağrı, Erzincan & 25 & $2,417.12$ & 0.05 \\
\hline Doğu Anadolu Bölgesi & 465 & $37,600.03$ & 0.79 \\
\hline Gaziantep & 14,133 & $1,108,242.22$ & 23.38 \\
\hline Malatya & 5,482 & $273,829.00$ & 5.78 \\
\hline Şanlıurfa & 9,956 & $799,383.86$ & 16.86 \\
\hline Kilis, Adıyaman, Mardin & 1,692 & $136,676.98$ & 2.88 \\
\hline Güneydoğu Anadolu Bölgesi & 31,263 & $2,318,132.05$ & 48.89 \\
\hline Ankara & 401 & $44,386.98$ & 0.94 \\
\hline Konya & 733 & $242,962.69$ & 5.12 \\
\hline Niğde & 161 & $34,000.85$ & 0.72 \\
\hline Karaman, Kayseri, Eskişehir, Aksaray, Çankırı, & 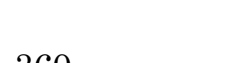 & ه & 145 \\
\hline $\begin{array}{l}\text { İç Anadolu Bölgesi } \\
\end{array}$ & $\begin{array}{l}360 \\
1,655\end{array}$ & $\begin{array}{l}68,802.82 \\
390.153 .34\end{array}$ & $\begin{array}{l}1.40 \\
8.23\end{array}$ \\
\hline Adana & 1,115 & $372,321.24$ & 7.85 \\
\hline Kahramanmaraş & 809 & $106,093.84$ & 2.24 \\
\hline Mersin & 2,272 & $198,085.42$ & 4.18 \\
\hline Isparta, Antalya, Hatay, Burdur, Osmaniye & 1,400 & $108,610.08$ & 2.29 \\
\hline Akdeniz Bölgesi & 5,596 & $785,110.58$ & 16.56 \\
\hline Aydın & 1,940 & $129,028.15$ & 2.72 \\
\hline Denizli & 4,153 & $176,681.27$ & 3.73 \\
\hline Manisa & 849 & $107,516.20$ & 2.27 \\
\hline İzmir, Muğla, Afyon, Uşak, Kütahya & 2,347 & $191,703.75$ & 4.04 \\
\hline Ege Bölgesi & 9,289 & $604,929.37$ & 12.76 \\
\hline
\end{tabular}

Kaynak: Anonim, 2016c

İyi tarım uygulamalarının yaygınlaşmasında verilen desteklerin önemli olduğu bir gerçektir. Ancak çiftçilerin alışılagelmiş üretimlerini bırakmaları, iyi tarım uygulamaları desteğinin işletmeler için ekonomik avantaj sağlamasına bağlıdır. Bu nedenle Türkiye'de konvansiyonel tarımdan iyi tarım uygulamalarına geçen işletmelerde, gelirdeki değişimin analiz edilip, desteklerin bu sonuçlar çerçevesinde yeniden düzenlenmesi gerekmektedir. Zira ekonomik olmayan hiçbir üretim faaliyetinin sürdürülebilir olmasını beklemek gerçekçi olmayacaktır.

Türkiye'de iyi tarım uygulamalarında ürün ve üretici sayısının artırılmasında, iyi tarım uygulamaları desteğiyle birlikte bu ürünlere olan pazarın da genişletilmesi gerekmektedir. İyi tarım ürünlerini konvansiyonel ürünlerden ayıran özelliklere dikkat çekilerek, tüketici bilincinin artırılmasında reklam faaliyetleri önemli oranda etkili olacaktır. $\mathrm{Bu}$ kapsamda televizyon başta olmak üzere kitle iletişim araçlarının kullanılması, çok sayıda tüketiciye daha kısa sürede ulaşma imkânı sağlayacaktır. Türkiye'de iyi tarım uygulamalarındaki gelişmeler sonucu, artan üretimle birlikte iç ve dış pazarlara daha sağlıklı ve güvenilir ürünler sunulacaktır. Bununla birlikte iyi tarım uygulamalarında kimyasal girdi kullanımına getirilen kısitlamalarla, doğal kaynaklar korunacak ve gelecek nesiller için sürdürülebilir bir üretim arzı da garanti altına alınmış olacaktır. 


\section{KAYNAKLAR}

Aba GÖ, Işın Ş 2014. Dünyada ve Türkiye'de İyi Tarım Uygulamalarının Gelişimi. XI. Ulusal Tarım Ekonomisi Kongresi, 3-5 Eylül, Samsun.

Adenle AA, Sowe SK, Parayil G, Aginam O 2012. Analysis of Open Source Biotechnology in Developing Countries: An Emerging Framework for Sustainable Agriculture. Technology in Society, 34 (3): 256-269.

Aerni P 2009. What is Sustainable Agriculture? Empirical Evidence of Diverging Views in Switzerland and New Zealand. Ecological Economics, 68 (6): 1872-1882.

Aksoy A, Dıvrak BB, Sütlü E 2013. İyi Tarım Uygulamaları El Kitabı. http://awsassets.wwftr.panda.org/downloads/itu_w eb_son.pdf. (Erişim tarihi: 29.09.2017).

Amekawa Y, Chuanb NC, Lumayagc LA, Tand GH, Wongd CS, Abdulra'ufe LB, Tanf HB, Taig WX, Tanh SM, Liui CH, Cheej JL 2017. Producers' Perceptions of Public Good Agricultural Practices and their Pesticide Use: The Case of MyGAP for Durian Farming in Pahang, Malaysia. Asian Journal of Agriculture and Rural Development, 7 (1): $1-16$.

Anonim 1973. Üçüncü Beş Yıllık Kalkınma Planı. http://www.kalkinma.gov.tr/Lists/

Kalknma\%20Planlar/Attachments/7/plan3.pdf. (Erişim tarihi: 12.09.2017).

Anonim 1987. World Commission on Environment and Development. Our Common Future. http://www.undocuments.net/our-common-future.pdf. (Erişim tarihi: 12.09.2017)

Anonim 2002. İklim Değiş̧ikliği Çerçeve Sözleşmesi. http://iklim.cob.gov.tr/iklim/Files/

Mevzuat/BM_iklimcerceve.pdf. (Erişim tarihi: 14.10.2017).

Anonim 2004. İyi Tarım Uygulamalarına İlişkin Yönetmelik. http://www.resmigazete.gov.tr /eskiler/2004/09/20040908.htm, (Erişim tarihi: 14.10.2017).

Anonim 2010. İyi Tarım Uygulamaları Destekleme Ödemesi Yapılmasına Dair Tebliğ. http://www.resmigazete.gov.tr/eskiler /2010/12/20101229M6-11.htm, (Erişim tarihi: 06.11.2017).

Anonim 2013. İyi Tarım Uygulamaları Destekleme Ödemesi Yapılmasına Dair Tebliğ. http://www.resmigazete.gov.tr/eskiler /2013/05/20130525-2.htm, (Erişim: 06.11.2017).

Anonim 2014. 2014 Yılında Yapılacak Tarımsal Desteklemelere İlişkin Karar. http://www.resmigazete.gov.tr /eskiler /2014 /04/20140412-2.htm, (Erişim tarihi: 07.11.2017).

Anonim 2016a. 2030 Sürdürülebilir Kalkınma Hedefleri. http://unesco.org.tr/dokumanlar /duyurular/skh.pdf. (Erişim tarihi: 22.11.2017).
Anonim 2016b. http://www.bmdergi.org/tr/?s= sürdürülebilir+kalkınma+hedefleri, (Erişim tarihi: 22.11.2017).

Anonim 2016c. İyi Tarım Uygulamaları İstatistikleri. http://www.tarim.gov.tr /Konular/BitkiselUretim/Iyi-Tarim-Uygulamalari/Istatistikler, (Erişim tarihi: 12.11.2017).

Anonim 2017. Alan Bazlı Destekler. http://www.tarim.gov.tr/Konular/TarimsalDestekler/Alan-Bazli-Destekler， (Erişim tarihi: 01.12.2017).

Ataseven Y 2014. Türkiye'de İyi Tarım Uygulamaları'na Yönelik Politikalardaki Gelişmeler. XI. Ulusal Tarım Ekonomisi Kongresi, 3-5 Eylül, Samsun.

Atış E 2004. Çevre ve Sürdürülebilirlik Boyutuyla Organik Tarım. http://www.bugday.org/portal/haber_detay.php?hid =466, (Erişim tarihi: 07.11.2017).

Baghasa H 2008. European System Related to Good Agricultural Practice (EUREPGAP). National Agricultural Policy Center, No: 26.

Boz I, Şahin A, Paksoy M, Giray FH, Direk M 2013. Çevre Amaçlı Tarımsal Arazilerin Korunması Programının (ÇATAK) Yayılması ve Benimsenmesi. TÜBİTAK Proje No: 1100747.

Çelik Y 2006. Sürdürülebilir Kalkınma Kavramı ve Sağlık. Hacettepe Sağlık İdaresi Dergisi, 9 (1):1937.

Davran MK 2007. Türkiye'de Kalkınma Sürecinde Kırsal Çevre Sorunları ve Toplumsal Bilinç Düzeyi. Sosyoloji Araştırmaları Dergisi, 10 (2): 37-52.

Dişbudak K 2008. Avrupa Birliği’nde Tarım-Çevre İlişkisi ve Türkiye'nin Uyumu. AB T.C. Tarım ve Köyişleri Bakanlığı, Dış İlişkiler ve AB Koordinas yon Dairesi Başkanlığı, Uzmanlık Tezi, 79 s.

Dulupçu M 2000. Sürdürülebilir Kalkınma Politikasına Yönelik Gelişmeler. Dış Ticaret Dergisi, 20: 46-70.

Gafsi M, Legagneux B, Nguyen G, Robin P 2006. Towards Sustainable Farming Systems: Effectiveness and Deficiency of the French Procedure of Sustainable Agriculture. Agricultural Systems, 90: 226-242.

Hasdemir M 2011. Kiraz Yetiştiriciliğinde İyi Tarım Uygulamalarının Benimsenmesini Etkileyen Faktörlerin Analizi. Ankara Üniversitesi, Fen Bilimleri Enstitüsü, Tarım Ekonomisi Anabilim Dalı, Doktora Tezi, 209 s.

Hess CE 1991. The US Department of Agriculture Commitment to Sustainable Agriculture (in Banr's Sustainable Agriculture Research and Education in the Field: A Proceeding). National Academy Press. Washington D.C.

İçel CD 2007. Avrupa Birliği Ülkelerinde İyi Tarım Uygulamaları ve Türkiye ile Karşılaştırılması. T.C. Tarım ve Köyişleri Bakanlığı, Dış İlişkiler ve Avrupa Birliği Koordinasyon Dairesi Başkanlığı, 
AB Uzmanlık Tezi, $114 \mathrm{~s}$.

Kaypak Ş 2011. Küreselleşme Sürecinde Sürdürülebilir Bir Kalkınma İçin Sürdürülebilir Bir Çevre. KMÜ Sosyal ve Ekonomik Araştırmalar Dergisi, 13 (20): 19-33.

Kuşat N 2013. Yeşil Sürdürülebilirlik için Yeşil Ekonomi: Avantaj ve Dezavantajları-Türkiye İncelemesi. Journal of Yaşar University, 29 (8): 4896 - 4916.

Marine SC, Martin DA, Adalja A, Mathew S, Everts KL 2016. Effect of Market Channel, Farm Scale, and Years in Production on Mid-Atlantic Vegetable Producers' Knowledge and Implementation of Good Agricultural Practices. Food Control, 59: 128-138.

Marsh JS 1997. The Policy Approach to Sustainable Farming Systems in the EU. Agriculture, Ecosystems and Environment, 64 (2): 103-114.

Menalled F, Bass T, Buschena D, Cash D, Malone M, Maxwell B, McVay K, Miller P, Soto R, Weaver D 2008. An Introduction to the Principles and Practices of Sustainable Farming. http://msuextension.org/

publications/AgandNaturalResources/MT200813A G. pdf. (Erişim tarihi: 12.11.2017).

Onions CT 1964. The Shorter Oxfort English Dictonary, Oxford: Clarendan press.

Öner G, Işın Ş 2010. Globalgap Eşdeğerlik Sertifikasyon Sisteminin Dünyadaki Örnekleri ve Türkiye'de Uygulanabilirliğinin İrdelenmesi. Türkiye IX. Tarım Ekonomisi Kongresi, 22-24 Eylül, Şanlıurfa.

Özmehmet E 2008. Dünyada ve Tükiye Sürdürülebilir Kalkınma Yaklaşımları. Journal of Yaşar University, 12: 3.

Polat F 2014. Azerbaycan'da Global G.A.P Tarım
Uygulamalarının Gıda Güvenliği Bakımından Değerlendirilmesi, Azersun Örneği. XI. Ulusal Tarım Ekonomisi Kongresi, 3-5 Eylül, Samsun.

Safley M 1998. How Traditional Agriculture is Approaching Sustainability. Biomass and Bioenergy, 14 (4): 329-332.

Subaşı OS, Uysal O, Aktaş E, Aydın B 2016. Turunçgil Üretiminde İyi Tarım Uygulamalarının Karşılaştırmalı Ekonomik Analizi: Mersin İli Örneği. XII. Tarım Ekonomisi Kongresi, 25-27 Mayıs, Isparta.

Tatlıdil FF, Boz İ, Tatlıdil H 2009. Farmers' Perception of Sustainable Agriculture and its Determinants: A Case Study in Kahramanmaraş Province of Turkey. Environment, Development and Sustainability, 11(6): 1091-1106.

Tıraş HH 2012. Sürdürülebilir Kalkınma ve Çevre: Teorik Bir İnceleme. Kahramanmaraş Sütçü İmam Üniversitesi İktisadi ve İdari Bilimler Fakültesi Dergisi, 2 (2): 57-73.

Turhan Ş 2005. Tarımda Sürdürülebilirlik ve Organik Tarım. Tarım Ekonomisi Dergisi, 11(1): 13 - 24.

Türkten H, Eryılmaz GA, Ceyhan V, Kılıç O 2014. Bafra İlçesinde Çevre Amaçlı Tarım Arazilerin Korunması Programının Değerlendirilmesi ve İyi Tarım Uygulamalarının Etkilerinin Sürdürülebilirliği. XI. Ulusal Tarım Ekonomisi Kongresi, 3-5 Eylül, Samsun.

Yeşil M 2016. Doğa Koruma Yaklaşımlarındaki Değişimlerin Dünyada ve Türkiye'deki Tarihsel Süreci. Türk Tarım-Gıda Bilim ve Teknoloji Dergisi, 4 (10): 867-876.

Yıldırım U, Öner Ș 2003. Sürdürülebilir Kalkınma Yaklaşımının Türkiye'ye Yansımaları: GAP'ta Sürdürülebilir Kalkınma ve Yerel Gündem 21. Çağdaş Yerel Yönetimler, 12 (4): 6-27. 